\title{
Article \\ Public Bus Transportation System Environmental Impact Projections Regarding Different Policy Scenarios-A LCA Study
}

\author{
Michelle Leichter ${ }^{1}$, Isadora Hackenhaar ${ }^{1,2} \mathbb{D}$ and Ana Passuello ${ }^{1, *}$ \\ 1 Postgraduate Program in Civil Engineering, Construction and Infrastructure (PPGCI), \\ Federal University of Rio Grande do Sul (UFRGS), Porto Alegre 90035-190, Brazil; \\ michelle.leichter@ufrgs.br (M.L.); isadora.correahackenhaar@ugent.be (I.H.) \\ 2 Sustainable Systems Engineering (STEN), Department of Green Chemistry and Technology, Faculty of \\ Bioscience Engineering, Ghent University, Coupure Links 653, B-9000 Ghent, Belgium \\ * Correspondence: ana.passuello@ufrgs.br
}

\section{check for} updates

Citation: Leichter, M.; Hackenhaar, I.; Passuello, A. Public Bus Transportation System Environmental Impact Projections Regarding Different Policy Scenarios-A LCA Study. Infrastructures 2021, 6, 169. https://doi.org/10.3390/ infrastructures 6120169

\section{Academic Editors: Ahmed W.}

A. Hammad, Carlos A. P. Soares and Assed N. Haddad

Received: 12 October 2021

Accepted: 26 November 2021

Published: 1 December 2021

Publisher's Note: MDPI stays neutral with regard to jurisdictional claims in published maps and institutional affiliations.

Copyright: (c) 2021 by the authors. Licensee MDPI, Basel, Switzerland. This article is an open access article distributed under the terms and conditions of the Creative Commons Attribution (CC BY) license (https:/ / creativecommons.org/licenses/by/ $4.0 /)$.

\begin{abstract}
Urban activities, such as transportation, are responsible for a large portion of energyrelated $\mathrm{CO}_{2}$ emissions. As the need for sustainable urban development increases, decision-makers embrace Life Cycle Assessment (LCA) as a reliable tool capable of generating scientifically based information on environmental impacts. However, there is still a lack of an analysis standard regarding the particularities of urban systems. Therefore, this research aims to define current and future environmental profiles, considering a case study of the public transport system in Porto Alegre, considering specificities of the urban context and different public policy scenarios through LCA. These results show that, although the transportation system management relies on the municipalities, the higher significance of environmental impacts depend on a national policy for using biodiesel in the diesel sold, which could lead to an increase of, for example, up to $9.4 \%$ of $\mathrm{CO}_{2}$ emissions from 2017 (baseline) to 2030. Finally, it is perceivable that to conduct a LCA to support decision-making in public urban services, a detailed approach is needed considering that technological variables interact with the territorial context and policy changes.
\end{abstract}

Keywords: life cycle assessment; sustainable urban development; urban mobility; environmentalfriendly transportation policies; infrastructures

\section{Introduction}

Cities are responsible for about $71-76 \%$ of energy-related $\mathrm{CO}_{2}$ emissions [1]. Through global campaigns and local actions, city planners are moving toward mitigation plans. Due to their large share of emissions from energy consumption in urban activities, strategies often target passenger transportation systems that in addition to requirements for rapidity, efficiency, flexibility, and safe transport, are now taking into account environmental aspects as a distinguishing factor [2].

These new trends demonstrate the current reality of the transport sector, which is still responsible for a huge proportion of the gas emissions studied; in Brazil 38\% of emissions came from this sector in 2019 [3]. However, there is a limited number of systematic assessments or actual implementation in sustainable forward transport policies, to the extent in which emission reduction targets are being achieved, or emissions reduced [1].

In this unfavorable scenario, Life Cycle Assessment (LCA) has already been proven to be a successful tool to support decision-making in an urban context. A previous literature review of over 70 scientific papers provided by Hackenhaar [4] shows the differentiation of the scope of LCA applications for urban spaces between urban system analysis - including energy, land use and mobility, among others-and global production/consumption analysis-including all cities' systems [5-7]. Although the current 
literature shows that there is still no consensus on the particularities of LCA for urban strategies and policies, there were important advancements in the field. The investigation focuses mainly on the discrimination of the multi-functionality of a system's projects to be taken into consideration during scope definition in LCA [6,8], as well as the allocation of impact due to the territorial context and geographical boundaries [6,9], including all socio-economic and cultural characteristics embedded in this technosphere. Thus, the central difference of Territorial LCA (TLCA, as defined by [7] to the 'conventional' LCA (the one defined in ISO 14,040 [10] would then be the careful definition of the objective and scope of the study by context delimitation, which would induce the consideration of multi-scale interactions between policy makers, infrastructure designers and operators, as well as users of urban places [6].

To the best of our knowledge, few passenger transportation LCA studies explicitly encompass this particularity of scope in its entirety. However, in recent years, LCA practitioners have begun to develop studies that border such specificities, especially considering geographical contexts to assess the impacts of passenger transportation systems more precisely. To support policy making, LCA studies have been developed on an urban and regional scale regarding the extension of rail lines [11], the comparison of personal vehicle and public transit use [12], the comparison of modal shares [12], an integrated analysis of transportation and land use [13], and a case study of evaluating taxis concerning zone and system changes [14], and a broad multi-scale analysis that includes the indirect (embodied) emissions in a city transportation system [15]. However, there is still a perceivable lack of studies on urban LCAs, including transportation research, from Latin America and Brazil, published in international journals. This gap implies that a broad range of socio-economic, cultural, and technological contexts are left aside in the literature. In most of these territories, restrictions of local investments in more expensive urban mobility infrastructure, such as metro and trains, and the low expectation of return on investment limit improvements of the service's environmental performance.

Thus, the main objective of this research is to investigate the current and future environmental profile of the Porto Alegre public bus transportation system in Brazil, regarding different public policy scenarios that affect the system and specificities of the city's context through TLCA recommendations. By contextualization, public bus transportation is chosen due to its social importance and greater susceptibility to municipal regulations. This paper advances the discussion on the particularities of the limiting variables of the system, taking into consideration TLCA in a time-based prospective approach to evaluate future emissions and impacts of different policies, assuming potential changes of using this transportation system.

\section{Materials and Methods}

The developed case study is based on the LCA technique according to ISO 14040, considering the methodological specifications provided by Loiseau et al. [7] regarding TLCA-type A. In TLCA-A, the objective and scope can be defined according to the consistent analysis of the territory's history supported by local databases and geographical data. The results of the analysis are a list of key system items and characteristics (e.g., stakeholders, stocks, networks, and environmental variables), quantified and georeferenced.

Following this perspective, the territory contextualization was used to define the key parameters of the LCA analysis. The following subsections describe the LCA choices based on that. The information collected helps to meet the objective and scope phases, and consequently the LCI and LCIA, including the system frontiers, scenarios, and the definition of impact indicators.

\subsection{Territory Context}

Porto Alegre is a metropolis located in southern Brazil that has a population of over 1.41 million people in an area of $496.83 \mathrm{~km}^{2}$. It is the tenth most populous city in Brazil. Regarding infrastructure, only $69.4 \%$ of public roads are urbanized [16]. Due 
to its size and population, according to local regulations [17], the city must have a City Development Plan (DP), as well as an urban Mobility Plan (MP). New versions of both DP and MP considering the transformations of the city's socioeconomic dimensions are expected to be published by 2021. According to the municipality, the next version of the DP will include all the Sustainable Development Goals (SDGs), extending the main structure and principles of the current plan to encompass sustainability. Within the thematic "Mobility and accessibility", the inclusion of SDG number 3 (Good health and well-being), 11 (Sustainable cities and communities) and 13 (Climate Action) stand out [18]. The diagnosis, published prior to the mobility plan (MP), uses a method developed by WRI Brazil as a reference, based on the diagnosis of the current reality of transport and a prognosis for future scenarios $[19,20]$.

According to reports, the current daily modes of transportation in the city are bicycle, bus, minibus, and ferryboat, as well as individual transport (including family cars, taxis, and ride-hailing apps) and cargo transportation, all connected by walking mode [20]. According to the same study, public bus and minibus transportation are the most used for commuting ( $40 \%$ of trips), followed by individual transportation (approximately $36 \%$ ). However, it is important to note that the results represent trends for 2003 (the latest research on behavior mobility found by WRI) and may not properly assess the present trends given the increase in the car fleet and the offer of transport service per mobile app.

\subsection{Objective and Scope}

Based on the value and need for the public transportation system in Porto Alegre, this LCA aims to generate emission indicators by diagnosing potential impacts of the current collective bus transportation system operation, and the projection of environmental impact variation according to public policies addressed related to system variables. Within this system, the main stakeholders are the transport users, the public and private companies licensed to provide the public transport service, and the Public Transport and Circulation Company (PTCC), which all interact in the system as demand, supply, and control, respectively. The main variables related to supply and demand and the system operation-which together give rise to economic relations between costs, profits, and tariffs-are the number of passengers carried, distances travelled, and vehicle energy efficiency.

Considering the vehicle's life cycle, the use phase releases the highest amount of emissions to the environment/air, especially due to combustion engines and the vehicle's long service life $[12,21]$. Given these claims, the reduction of emissions and impacts from public transport can follow changes in three variables and some key parameters for the use phase: fuel consumed, vehicle characteristics, and operational routine. According to the variables presented, two decision-making levels were identified by the agents involved: national and municipal, as shown in Figure 1.

\subsubsection{System Boundaries and Period of Study}

For this research, the use and operation of the transportation service are considered. The production and maintenance processes of buses and civil infrastructure were not analyzed, as these processes do not have high participation in the impacts during the bus lifespan (up to a maximum of 14 years) [22]. Moreover, in the absence of locally collected data, the inclusion of capital goods may increase outcome uncertainties [23]. Impacts related to fuel for the use phase include production, transportation, and consumption/use impacts (combustion during operation).

The inventory time limit considers aggregated data for 2017, and the study period is from 2017 (the latest data gathered by this research) to 2030. The use of these units is consistent with the indicators suggested by the SDG committee and ISO 37120. The end of the period coincides with the SDG deadline to meet the fortnightly targets and the schedule for the next revisions of the city's DP and the MP. 


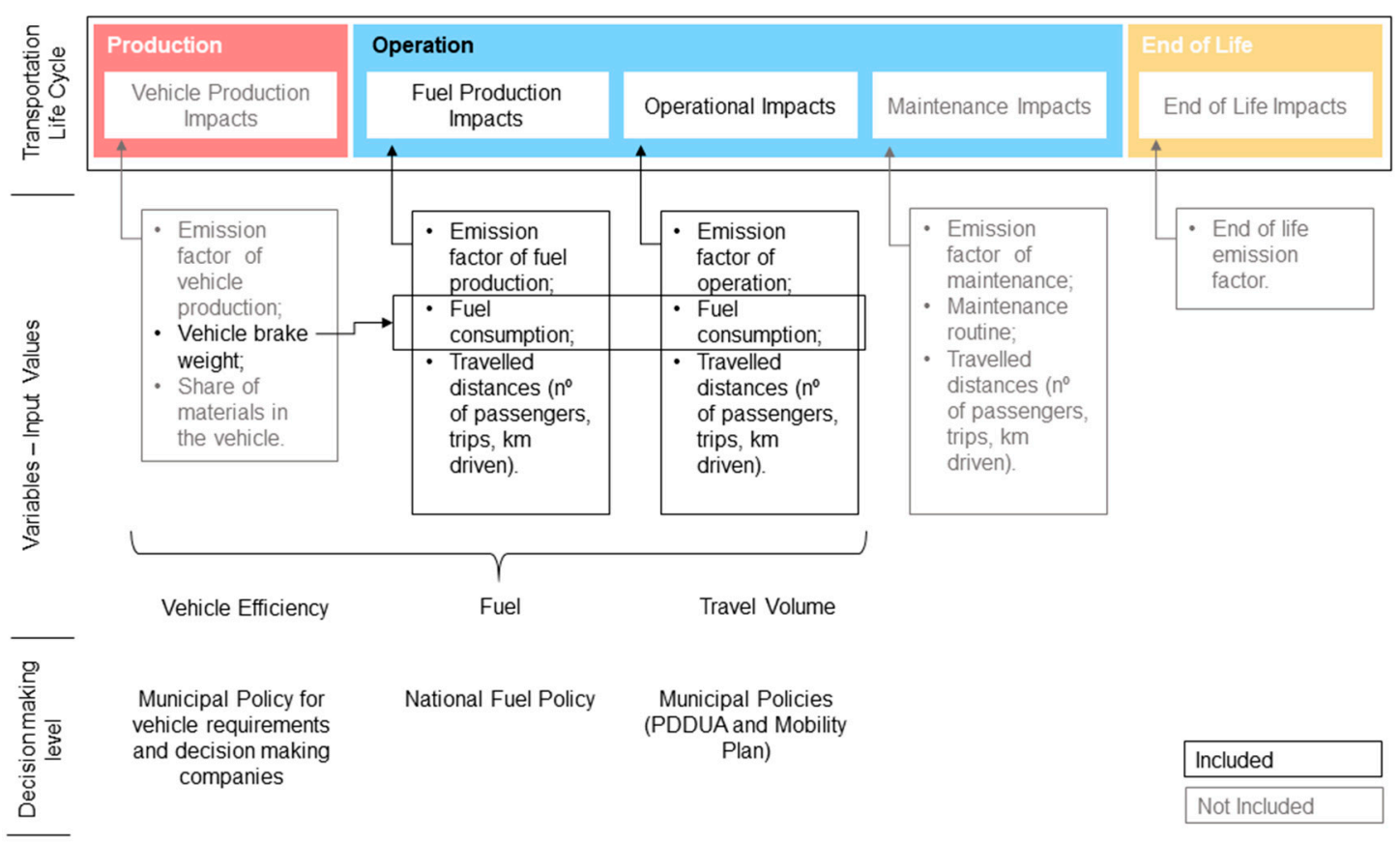

Figure 1. Life cycle phases with the respective variables susceptible to changes by public policies for mitigation purposes. Based on Garcia et al. (2015).

\subsubsection{Functional Unit}

In this study, a common unit is used as a reference to consider a joint projection of changes in scenarios. The common unit considered is the time function, which is one year of transportation services. The study initially represents the yearly total emissions of the system following the purpose to generate indicators that are consistent with those suggested by the SDG commission and the ISO 37120 standard [24,25].

However, for purposes of enabling decision-making by comparing scenarios at the municipal policy level, this indicator is not favorable, as it disregards variables on the distribution and volume of service according to demand [20]. Thus, the most appropriate indicator to support decision-making at this level is the one that communicates the impacts related to variables sensitive to interventions. Therefore, the common unit considered is the kilometers traveled, considering annual changes in vehicle efficiency values and fuel composition. This correlates with Nordelöf and colleagues' study [26] where is stated that the Functional Unit (FU) of complete LCAs is defined as a vehicle life cycle, which is specified by the total number of $\mathrm{km}$ driven.

\subsection{Inventory}

\subsubsection{System Boundaries and Period of Study}

Fuel consumption, distances travelled, and vehicle efficiency and substitution material - primary data-were provided by demand from the PTCC and Public Transportation Association regarding the year 2017. System's characteristics for analysis and the historical data were retrieved from an interview with the PTCC in 2018 (see Supplementary Material for the report of the interview).

The available data from 2017 was applied to the diagnosis of the current impacts generated by the system. The assumptions intrinsically related to the system boundary are described as follows. For the projection of future scenarios, existing public policies and potential changes on the operational variables were considered to create a prospective analysis from 2018-2030. Accordingly, some inventory changes were assumed over time, taking into account projections of changes throughout the years until 2030. 
Moreover, mechanical requirement regulations for the purchase of new vehicles in the city have historically been revised following the European heavy-duty engine regulatory updates. New buses must have Euro V engines, which have more efficient combustion with lower emission factors of particulate matter. However, older vehicles with Euro II, III and IV engines, with lower efficiency rates, are still running due to the service lifespan (reported to have a maximum value of 14 years). Despite such advancements in engine transition, it is worth noting that as buses are replaced, efficiency generally decreases. This occurs mainly as all new vehicles purchased are required to use air conditioning and the presence of automatic transmission is also recommended. Both of these characteristics decrease the vehicle's overall efficiency. Furthermore, according to the city's Public Transportation Association, all buses currently run on diesel S10 (10 ppm); nonetheless, the gradual substitution from pure diesel to a higher percentage of biodiesel in the mix also decreases efficiency, as demonstrated in Table 1.

Table 1. The scenarios change over time according to the variables proposed in this paper.

\begin{tabular}{|c|c|c|c|c|c|c|c|}
\hline \multirow{2}{*}{$\begin{array}{c}\text { Variable } \\
\text { Year }\end{array}$} & \multicolumn{3}{|c|}{ Fuel (Diesel S10, Biodiesel BXX) } & \multicolumn{3}{|c|}{ Efficiency System (1/km) } & \multirow{2}{*}{$\begin{array}{l}\text { Vehicles Replaced } \\
\text { (No.) }\end{array}$} \\
\hline & *sB15 & sB20 & sB30 & SB15 & sB20 & sB30 & \\
\hline 2017 & ** B9 & B9 & B9 & $4.76 \times 10^{-1}$ & $4.76 \times 10^{-1}$ & $4.76 \times 10^{-1}$ & 0 \\
\hline 2018 & B10 & $\mathrm{B} 10$ & $\mathrm{~B} 10$ & $4.77 \times 10^{-1}$ & $4.77 \times 10^{-1}$ & $4.77 \times 10^{-1}$ & 0 \\
\hline 2019 & B11 & B11 & B11 & $4.81 \times 10^{-1}$ & $4.81 \times 10^{-1}$ & $4.81 \times 10^{-1}$ & 116 \\
\hline 2020 & B12 & $\mathrm{B} 12$ & $\mathrm{~B} 12$ & $4.86 \times 10^{-1}$ & $4.86 \times 10^{-1}$ & $4.86 \times 10^{-1}$ & 152 \\
\hline 2021 & B13 & $\mathrm{B} 13$ & $\mathrm{~B} 13$ & $4.92 \times 10^{-1}$ & $4.92 \times 10^{-1}$ & $4.92 \times 10^{-1}$ & 160 \\
\hline 2022 & B14 & B14 & B14 & $4.95 \times 10^{-1}$ & $4.95 \times 10^{-1}$ & $4.95 \times 10^{-1}$ & 145 \\
\hline 2023 & B15 & B15 & $\mathrm{B} 15$ & $4.99 \times 10^{-1}$ & $4.99 \times 10^{-1}$ & $4.99 \times 10^{-1}$ & 137 \\
\hline 2024 & B15 & $\mathrm{B} 16$ & B17 & $5.02 \times 10^{-1}$ & $5.03 \times 10^{-1}$ & $5.03 \times 10^{-1}$ & 162 \\
\hline 2025 & B15 & B17 & B19 & $5.04 \times 10^{-1}$ & $5.05 \times 10^{-1}$ & $5.05 \times 10^{-1}$ & 101 \\
\hline 2026 & B15 & B18 & B21 & $5.05 \times 10^{-1}$ & $5.06 \times 10^{-1}$ & $5.06 \times 10^{-1}$ & 16 \\
\hline 2027 & B15 & B19 & $\mathrm{B} 23$ & $5.05 \times 10^{-1}$ & $5.06 \times 10^{-1}$ & $5.07 \times 10^{-1}$ & 0 \\
\hline 2028 & B15 & $\mathrm{B} 20$ & B25 & $5.05 \times 10^{-1}$ & $5.06 \times 10^{-1}$ & $5.07 \times 10^{-1}$ & 0 \\
\hline 2029 & B15 & $\mathrm{B} 20$ & $\mathrm{~B} 27$ & $5.07 \times 10^{-1}$ & $5.08 \times 10^{-1}$ & $5.10 \times 10^{-1}$ & 84 \\
\hline 2030 & B15 & $\mathrm{B} 20$ & B30 & $5.07 \times 10^{-1}$ & $5.08 \times 10^{-1}$ & $5.10 \times 10^{-1}$ & 0 \\
\hline
\end{tabular}

* sB15 (scenario 1); sB20 (scenario 2); sB30 (scenario 3); s(scenario); B(biodiesel); XX(\% OF biodiesel in 2030). ** BXX: fuel compound with "XX" percentage of diesel replacement with biodiesel by 2030 (e.g., in B10, there was diesel with 10\% biodiesel in 2018).

Therefore, diesel composition scenarios were generated over time considering the national law [27], which states that diesel should have a biodiesel composition of $9 \%$ by 2017, $10 \%$ by 2018 and $11 \%$ by 2019 increasing by $1 \%$ yearly until 2023. Based on national resolutions, which encourage the voluntary use of mixtures B20 and B30 [28], possible future scenarios include the effect of the gradual substitution of diesel by biodiesel over time. Thus, three scenarios are considered, including changes in fuel composition already provided for by law. In a less optimistic first scenario (sB15), only such national resolution is considered, with no future changes appraised in fuel composition until 2030. Furthermore, two distinct scenarios are suggested from 2023 onward, the use of B20 is estimated in scenario 2 (sB20) and B30 in scenario 3 (sB30) by considering a gradual linear shift of use of this fuel compound with impacts calculated following the options presented in Table 1.

Changes in vehicle efficiency are also expected due to fleet replacement. The available data [29] classifies the Vehicle Consumption Category according to size and height (Micro, Light, Heavy, Bus $6 \times 2$; Special), the engine position (central, front, and rear), the presence of air conditioning, and the type of gearbox (manual or automatic) (see Supplementary Material for details of efficiency of categories). In 2017, the fleet had 1651 vehicles, acquired from 2006 to 2016. That is, from 2019 onwards, there would be a gradual replacement of the fleet, as the vehicles reach their maximum lifespan.

Hence, each scenario considers the average fuel consumption per kilometer traveled and the percentage of fleet replacement over the years, not considering the increase and 
reduction of the total fleet volume due to the lack of data for approximation. It also considers the municipal standard that defines the requirements for purchasing new vehicles, which states that inclusion to the fleet will only be allowed for new (zero kilometers travelled) and air-conditioned vehicles. As emerging technologies to be introduced into the public transport bus market and their respective efficiency are not yet known, no technological changes were examined. The simulated annual changes according to these scenarios are detailed in Table 1, as well as the average system efficiency values as a function of the number of vehicles in each class and their corresponding efficiency in 2017. To reach such values, both fuel transition and vehicle substitutions were taken into account for each scenario throughout the years.

The yearly distances travelled were estimated according to data provided from 2017. Accordingly, the travelled distance for following is treated as stationary, considering that the timetable and routes would not be altered in the coming years, maintaining the value of approximately 109.5 million kilometers traveled in 2017. On the other hand, changes in consumption due to the variation in capacity (number of people transported) were neglected in this study and this approach is justified because the primary data provided by PTCC are average data without information on this variation.

\subsubsection{Background Data}

An impact analysis of diesel and biodiesel production processes, as well as their combustion, is produced according to inventory data taken from the Ecoinvent database, version 3.6 [30]. The adaptation of background inventory data is considered satisfactory as it follows the literature and data available from producers and distributors of products in the national context when available.

As described in the system boundary, diesel production processes (from extraction to the final product), biodiesel production, transportation of the composite product to the bus parking lot, as well as bus use (combustion) are included. Possible emissions from the fuel blending process are not considered. The emission values for the use process were also added from the GHG emission factors reported in [31]. Furthermore, the lower calorific value of biodiesel compared to diesel fuel was taken into account, as biodiesel blends also present lower calorific values than pure diesel, and therefore, a more significant amount of fuel is required to produce the same power [32]. The base value chosen for diesel was 36.12 MJ/liter and for biodiesel 34.41 MJ/liter as indicated by [33].

\subsection{Life Cycle Impact Assessment}

The environmental impact assessment of the system was calculated using the Simapro v9.1 software, faculty version. The impact categories (ICs) chosen for evaluation are those relevant to the system studied. Heavy vehicles (buses and trucks) are responsible for a large fraction of nitrogen oxides and sulfur emissions [34]. The main products generated by fuel combustion are carbon dioxide $\left(\mathrm{CO}_{2}\right)$ and water vapour $\left(\mathrm{H}_{2} \mathrm{O}\right)$. Other gases generated are carbon monoxide (CO), hydrocarbons ( $\mathrm{HC}$ ), nitrous oxides (NOx), sulfur compounds (SOx), particulate matter (PM), and dioxins, directly or indirectly causing environmental impacts and consequences on human health $[34,35]$. In addition to these emissions, some specific indicators suggested by the UN [36] for the SDGs were measured from the LCA impact characterization. Thus, three ICs were chosen for analysis in this study: global warming potential (GWP), human toxicity, (HT) and abiotic depletion (AD) regarding fossil fuels. The impact categories chosen also correlate with previous studies published on a similar theme [11].

As there are no impact characterization methods available for the Brazilian context and its different regions, the literature was consulted (RAICV Report on Recommendations of Impact Assessment Models for the Brazilian Context). According to the recommendation of ILCD [37] and RAICV [38], the characterization method chosen was CML 2002 for both GWP and HT. 


\section{Results}

The projections for future scenarios were developed from combining the variables described in Table 1. Scenarios 1 to 3 have possible combinations of fuel changes (sB15: following national law with stagnation in 2023, sB20: reaching B20 from 2028 onward, sB30: reaching B30 only on 2030), the distances travelled remain stationary. All scenarios consider the fleet renovation for new vehicles with air conditioning and automatic gearboxes. Between 2017 and 2018, all scenarios include changes in fuel but no fleet changes. Once the fleet begins to be renewed in 2019, the scenarios are also affected by this variable, which implies a slight increase in impacts and decrease in efficiency over the following years. From 2019 onwards, the scenarios remain constant in trend, presenting fleet changes except for 2027, 2028, and 2030, where there are no vehicle substitutions.

Considering the sB15 scenario, the total and percentage impacts of diesel decrease over the years with the gradual replacement of biodiesel until 2023, when the increase in percentage of biodiesel in the mix ceases. However, it is important to highlight that the impact of diesel is the most representative throughout all the years considering that its percentage contribution in the analysis is quantitatively greater; in GWP it amounts to $79.7 \%$ with approximately $1.41 \times 10^{8} \mathrm{~kg} \mathrm{CO}_{2}$-eq. in 2030. The impact of biodiesel corresponds to just over $20.3 \%$ with around $3.59 \times 10^{7} \mathrm{~kg} \mathrm{CO}_{2}$-eq. in the same year. Moreover, for the HT sB15 scenario, our findings show that by 2017 diesel encompasses $54.7 \%$ (about $8.01 \times 10^{6} \mathrm{~kg} 1.4$-DB-eq.) and biodiesel almost $45.3 \%$ (about $6.64 \times 10^{6} \mathrm{~kg} 1.4$-DBeq.) of impacts. In contrast, regarding the AD sB15 scenario, a clear differentiation can be observed compared to the previous impact categories analyzed.

Different from GWP and HT, in AD the increase in biodiesel presents a reduction in impacts. On the other hand, the decrease in vehicle efficiency, and consequently, the increase in both liters consumed per kilometer, heightens environmental impacts related to $\mathrm{AD}$, generating two inversely proportional variables, which create nonlinearity perceived in the graph. For instance, in 2018 there is a reduction of almost $1 \%$ in impacts compared to 2017 , considering that there is a substitution from B9 to B10, but no vehicles are replaced. In comparison, from 2018 to 2019 there is an increase of about $0.2 \%$ considering that despite a transition between B10 to B11, 116 vehicles are substituted. Additionally for the AD sB15 scenario, it is worth highlighting that even by 2030 Diesel confines $95.9 \%$ (about $1.97 \times 10^{9} \mathrm{MJ}$ ) and biodiesel only $4.1 \%$ (about $8.27 \times 10^{7} \mathrm{MJ}$ ) of impacts.

This significant difference in the contribution of both fuels related to all the impact categories shown happened mostly due to the fact that in GWP for $1 \mathrm{~kg}$ of fuel the variation between impacts related to diesel and biodiesel is roughly $16 \%$. On the other hand, in HT, biodiesel presents a $77 \%$ higher contribution than diesel. Finally, AD diesel offers a $63 \%$ higher contribution than biodiesel. These differences can be clearly seen in Figure 2.

In the following scenarios, there is a change in the diesel composition that is foreseen for up to 20 or $30 \%$ of biodiesel beginning in 2023. From there on, the impacts tend to increase or slightly decrease depending on the impact category observed. Regarding the sB20 scenario, for both GWP and HT, diesel and biodiesel reached their lowest impact in the base year of 2017. In contrast, considering AD, the lowest total impact found was in 2028, a year in which there is no replacement of vehicles and use of B20. Furthermore, sB20 shows that the GWP impact increases from $1.61 \times 10^{8} \mathrm{~kg} \mathrm{CO}_{2}$-eq. in 2017 to about $1.81 \times 10^{8} \mathrm{~kg}$ $\mathrm{CO}_{2}$-eq. in 2030, in which biodiesel encompasses $26.5 \%$ of the GWP impact. According to the GWP, HT increases its total emissions over the years from almost $1.47 \times 10^{7} \mathrm{~kg}$ 1.4-DB-eq. in 2017 to more than $2.34 \times 10^{7} \mathrm{~kg}$ 1.4-DB-eq. in 2030 in the sB20 scenario. As happened in GWP, the total and the percentage impacts increased over the years, but it is evident that the same happened in HT much more significantly. Whereas in GWP, the total impact increased by $11.9 \%$ in HT and there was a 59.4\% increase between 2017 and 2030 as seen in Figure 3. 

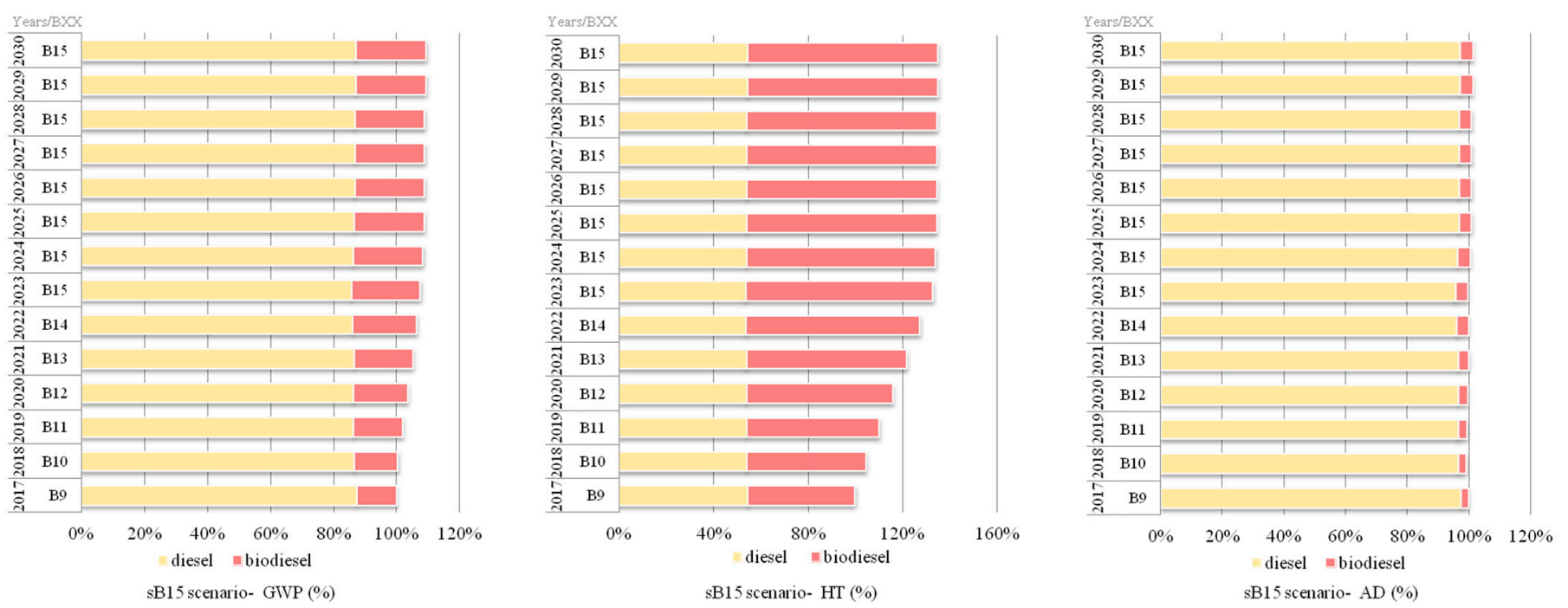

Figure 2. Global warming potential (GWP), Human Toxicity (HT), and Abiotic Depletion (AD) impact categories (in percentage $\mathrm{kg} / \mathrm{km}$ ) considering the first scenario $\mathrm{Sb} 15$.
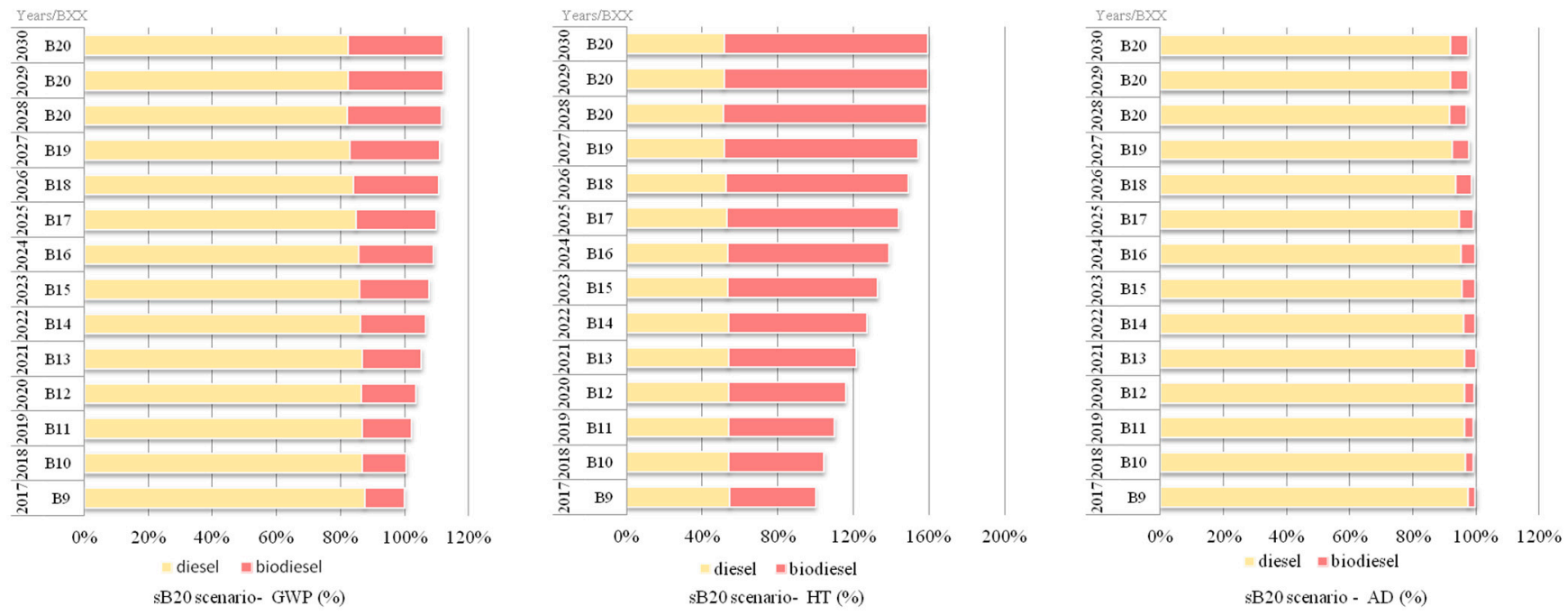

Figure 3. Global warming potential (GWP), Human Toxicity (HT) and Abiotic Depletion (AD) impact categories (in percentage $\mathrm{kg} / \mathrm{km}$ ) considering the second scenario $\mathrm{Sb} 20$.

Once again contrasting GWP and HT, in AD the increase of biodiesel presents a reduction in impacts, and from 2017 to 2030 there is a reduction of almost $2.5 \%$ of impacts. However, in 2028, the year in which there is no replacement of vehicles and B20 as fuel is the year with the lowest impact value, $1.97 \times 10^{9} \mathrm{MJ}, 2.9 \%$ less than 2017 . This result makes it clear not only the importance of substituting the energy source in contributing to environmental impacts, but also the vehicular efficiency itself.

It is also worth noting that from 2023 onwards, the most significantly modified scenario within these sets is the one with the most fuel change (sB30) as seen in Figure 4. Differentiation among scenarios is best described in the HT graphs due to its greater sensitivity to fuel changes. This difference between the chosen scenarios is more easily noticed in situations where the fuel used until 2030 changes to B30 as the magnitude of the impacts generated by the fuel with the highest biodiesel content, B30, is greater than B20 or B10 when compared. 

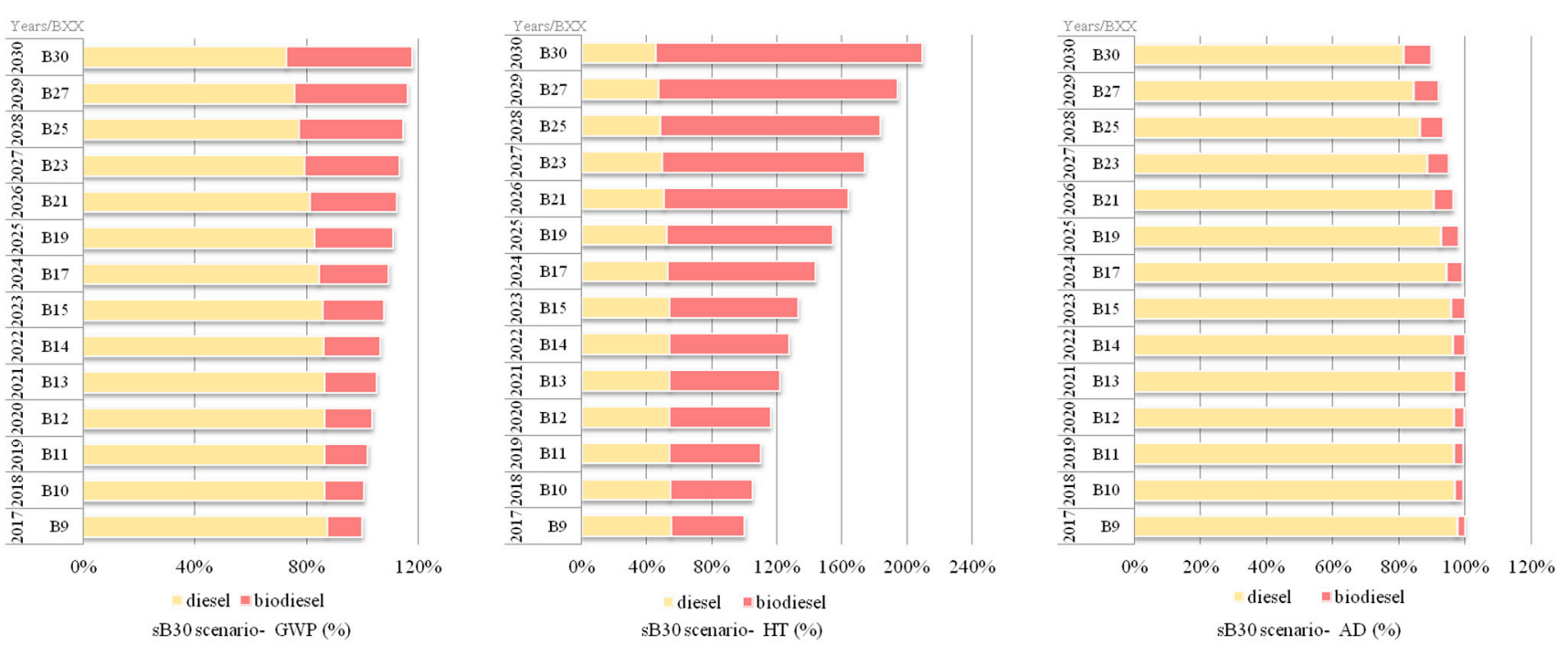

Figure 4. Global warming potential (GWP), Human Toxicity (HT) and Abiotic Depletion (AD) impact categories (in percentage $\mathrm{kg} / \mathrm{km}$ ) considering the second scenario $\mathrm{Sb} 30$.

Similarly, in scenario sB30, the highest GWP impact values are at the end of the period (2030) showing an increase in biodiesel at its highest in the mix. Between the base scenario in 2017 and the scenario that considers fuel, vehicles substitutions, and efficiency changes, there is an emission difference of $2.89 \times 10^{7} \mathrm{~kg} \mathrm{CO}_{2}$-eq. by 2030. This difference represents an increase of $17.9 \%$ in GWP emissions from 2017 and 2030. As in the previous scenario, the impacts of $\mathrm{HT}$ in sB30, both the total and percentage impacts, increase over the years, from $1.47 \times 10^{7} \mathrm{~kg}$ 1.4-DB-eq. in 2017 to $3.06 \times 10^{7} \mathrm{~kg}$ 1.4-DB-eq. in 2030 with an increase of approximately 109.0\% between 2017 and 2030. Regarding AD from 2017 to 2030 there is a reduction of approximately $10.4 \%$ of impacts. In this case, 2030 is the year with the least accounted for impact, about $1.82 \times 10^{9} \mathrm{MJ}$. In comparison, 2017 and 2021 are the years in which we identified the highest impact values, both at $2.03 \times 10^{9} \mathrm{MJ}$, even considering that in 2017 there were no changes in the fleet and the use of B9 in the mix. In 2021, 160 vehicles were replaced. Thus, considering $\mathrm{AD}$, the low percentage of biodiesel adhered to the mixture and a large number of replacements negatively influence the final results. The results demonstrate the potential of renewable fuels related to the reduction of abiotic depletion, which is an obvious conclusion considering the replacement of diesel, a fossil fuel, in the scenarios by such a renewable source.

For the GWP and HT impacts evaluated in this study, emission values are more likely to increase in the coming years. AD instead tends to decrease, especially considering the higher percentages of biodiesel considered in scenario 3 (Sb30) as shown in Figure 4. Moreover, for all impact categories, in addition to the increase in emission volumes (GWP and HT) or the decrease (AD), a division into three result sets is observed. For the GWP and HT impacts evaluated in this study, emission values are more likely to increase in the coming years. AD instead tends to decrease, especially considering the higher percentages of biodiesel considered in scenario 3 (Sb30). For all impact categories, in addition to the increase in emission volumes (GWP and HT) or the decrease (AD), a division into three result sets is observed. In this case, the sets are mainly related to the combination of fleet changes, kilometers travelled, and a linkage to the amount of fuel consumed per year during the study period. Moreover, there are expressive variations between the impacts of replacing diesel with biodiesel for the categories examined. For both HT and GWP, the worst scenarios in terms of emissions are those that consider the highest use of biodiesel in diesel, as emission levels tend to rise with replacement levels according to the energy equivalences. Thus, the highest impact values were identified in Sb30 (in 2030, more specifically). In contrast, the lowest values in AD are also in Sb30 in the same year (also in 2030). Finally, it is worth highlighting that from 2017 to 2023 all scenarios align as both 
biodiesel levels and fleet efficiency are considered the same, mainly due to national policies that establish values between this particular time.

Ultimately, it is also important to mention the specifics of Brazilian biodiesel compared to both diesel and other producers outside Brazil, with data gathered from the Ecoinvent database version 3.6 [30]. The production of $1 \mathrm{~kg}$ of pure soy bean oil in Brazil generates $4.88 \mathrm{~kg} \mathrm{CO}$-eq. In comparison, diesel production in the country for $1 \mathrm{~kg}$ of fuel is approximately $0.44 \mathrm{~kg}$, while biodiesel production in the United States (US) is close to $1.01 \mathrm{~kg}$. Therefore, Brazilian biodiesel production, considering GWP, causes $91 \%$ more impacts compared to the same amount of diesel produced in the country. Additionally, when compared to biodiesel produced in the US, the difference is also significant as the Brazilian product generates $80 \%$ more impacts during its production stage.

\section{Discussion}

The results show that the different variables considered in the analysis have different importance according to the impact category analyzed. Nonetheless, for all impact categories and scenarios the highest or lowest level of emissions will be achieved in 2030, in which all scenarios will be stagnated until 2023. This means that if the only changing parameters in the system in the near future are the ones already foreseen by law (use of buses with air conditioning and the use of diesel with $15 \%$ biodiesel), there will be an increase of yearly impacts based on two of the three categories analyzed. In the case of GWP, although the same scenario represents the highest values of emissions, emissions in 2030 would still tend to be higher than in 2017 due to the mildly lower environmental performance of biodiesel regarding this impact.

Although the use of biodiesel in diesel influences the increase in the impacts of GWP, its effect is substantially more relevant regarding HT as the environmental impacts attributed to biodiesel compared to diesel were significantly higher compared to this category. The remarkably high impacts of biodiesel on HT are correlated with previous notions of fuel in the transport sector and its main deficiency is the increase of NOx in the atmosphere added to the production of this fuel compared to diesel, however solutions to this problem have not yet been fully developed [39]. The literature [40] also highlights these drawbacks in biodiesel use on transportation fuel, considering its correlation on the increase in emissions of not only nitrogen oxides (NOx), but also PM10, nitrous oxide, as well as nutrients such as nitrogen and phosphorous; the latter was the main agents for eutrophication.

In general, it can be concluded that the replacement of diesel with biodiesel could generate a significant reduction to mitigate emissions for the transportation system, given the high fuel consumption values. However, Nocker et al. [41] emphasize that biodiesel offers numerous advantages, especially considering greenhouse gas emissions; nonetheless, this fuel still presents high impacts in relation to public health and the environment, as perceived in the scenarios evaluated in the HT impact category. In relation to AD, research suggests [42] that considering the various compounds, such as metal and fossil energy catalysts, the depletion of these resources is higher when compared to biodiesel whose compounds are limited to mercury, water and sodium chloride $(\mathrm{NaCl})$ used in sodium hydroxyde $(\mathrm{NaOH})$ production. Therefore, it should be taken into account that the increase of biodiesel in the mixture would slightly diminish the impacts related to AD.

Bearing in mind such idiosyncrasies, future national policies should focus on analyzing the context as a whole through different impact categories before creating policies without a territorial and profound notion of the specificities of each location. Moreover, in the event of increased use of B20 and B30 fuels, the impact of land use and water scarcity-not evaluated in this research — should be considered as an increased demand for biodiesel oil may in the future alter market dynamics of agricultural products [33,38].

It is also worth noticing that the results demonstrate fuel technology as the one variable that generates greater sensitivity in the results, and the greatest power of decision in the reduction of impacts, in this case, at a national level. However, urban system impact analyses usually aim at providing scientific-based information for local actions. Here, the 
operational variables, including mileage and vehicle efficiency and substitution, are highlighted for the evaluation of the overall system yearly performance. City transport route planning, as well as the timetable and number of stops, would be the means to changes focused on increasing system efficiency. All these variables would then influence the distances travelled and the volume of fuel consumed, and therefore the environmental impact of the system. Improving the distribution of routes throughout the MP would lead to an improvement in the overall environmental efficiency of the system. Improvements could also be achieved by the revision of the DP as it assesses and defines population density, predominantly residential, commercial, agricultural and industrial regions. According to the AR5 study [1], infrastructure and urban form are directly related to environmental emissions.

Besides the environmental profile, this research brings important discussion regarding the use of LCA adapted to territorial analysis that includes urban systems. With data collected locally and with geographic reference added to population flows of urban mobility, the proposed model creates a site-specific LCA and a diagnosis of national and local decrees aggregated to the creation of three prospective scenarios, making the model itself the most realistic possible. Simultaneously, the lack of data regarding the end of life and production of vehicles is a limiting factor in the analysis. Furthermore, the superficial suggestions of adherence to new technologies by stakeholders, such as an introduction to electric vehicle in the public transportation fleet, were also limiting.

Finally, we highlight three aspects of the method: the use of context in the objective and scope definition, the impact indicators used, and the presentation of results.

\subsection{Context in the Objective and Scope Definition}

In an interview with PTCC, different variables were identified that could be changed by public policies: fuel, fleet efficiency, and operating variables. Likewise, the strategic levels of each of these policies, national or local/municipal were understood and were differentiated by the National SDG Commission [25]. Only then were the objective and scope defined.

Regarding the definition of scenarios, when studying a public transport system, such as the city of Porto Alegre, the evaluation of specific policies was initially defined related to the system's technology, which is complex by itself. In the example studied, the competitiveness of the collective bus modal concerning other urban modes indicates that it is likely that the scenarios of replacing the fleet with vehicles with air conditioning, the increase in kilometres travelled and the decrease in the number of passengers transported is among the most anticipated projections. However, they depend on the financial capacity of public agencies to encourage licensed companies to tailor the service to the needs of the interested public.

Moreover, indicators such as the SDGs [43] and the ISO 37,120 [24] require impacts demonstrated according to total values, as in the studies by Cano et al. and Garcia et al. [44,45]. In these cases, the final analysis will be through the common unit: one service year. Considering that in municipal policies the function of the system is essential [7,46], in the case study the analysis is performed with the normalization of the results of efficiency and operation of the transport system, allowing to evaluate changes in the following years and ensuring that they would involve the same ratio of kilometers travelled.

\subsection{Impact Indicators}

According to the history of urbanization in Brazil (environmental degradation and lack of sanitation infrastructure) [47], public policies currently do not have practical goals to achieve urban sustainability and other global objectives. Adopting the SDGs creates new opportunities for city planning. In this study, two impacts identified among the SDG indicators were included. They are indicators of $\mathrm{CO}_{2}$-eq. emissions and respiratory diseases. The case study demonstrates divergence between outcome trends when analyzing different impact categories. The results show that, while the $\mathrm{CO}_{2}$ emissions of the system tend to increase slightly in the future, the impacts of human toxicity have tended to increase 
substantially over the years. It demonstrates the importance of using a tool with welldefined and transparent assessment methods and reinforces that different types of impacts must be evaluated, as not all decisions have the same tendency for all potential impacts.

Researchers [5] raise a point, namely that the methods reviewed by them are not prepared to make comparative statements between cities or regions due to the lack of a common functional unit. Although widely used for comparisons in decision making, applying LCA to compare cities or regions still presents several barriers to transposition. Indicators such as those proposed by the SDG campaign aim to create a historical statistical database that can assess the performance of the city itself to inform decision-makers about the policies implemented. Therefore, the development of regulations for LCA in cities should not follow the same principles applied to LCA guidelines for products [10] concerning comparative decision making between complex multifunctional units, that is, cities or urban systems as the intrinsic characteristics of cities (related to the system function) add complexity to the communication of the indicators that compare them.

\subsection{Presentation of Results}

The results of the case study, as well as other LCA surveys in the urban territory, are designed to inform decision-makers (in this case, the PTCC and service providers) about the potential variation in system impacts. Above all, one of the most important points to be discussed is the presentation of the results as these should be reported to non-LCA specialists.

The case study brings the scenario approach according to [48], that stresses as the number and variety of possible scenarios for an analysis can be infinite, a possible solution is to use extreme scenarios, which can help to define other plausible scenarios, or used when there is insufficient data on changes over time. This "theory" is in accordance with the one proposed by [49] when they suggest the distribution of scenarios based on the "scenario trumpet". The results of the scenarios according to Figures 2-5 explicitly demonstrate the environmental profile of the system with current data and its trends from future projections and represent a scale of different potential future results. This method of evaluating and representing results can provide more accurate information for the creation and management of combined goals to reduce environmental impacts in public policies.
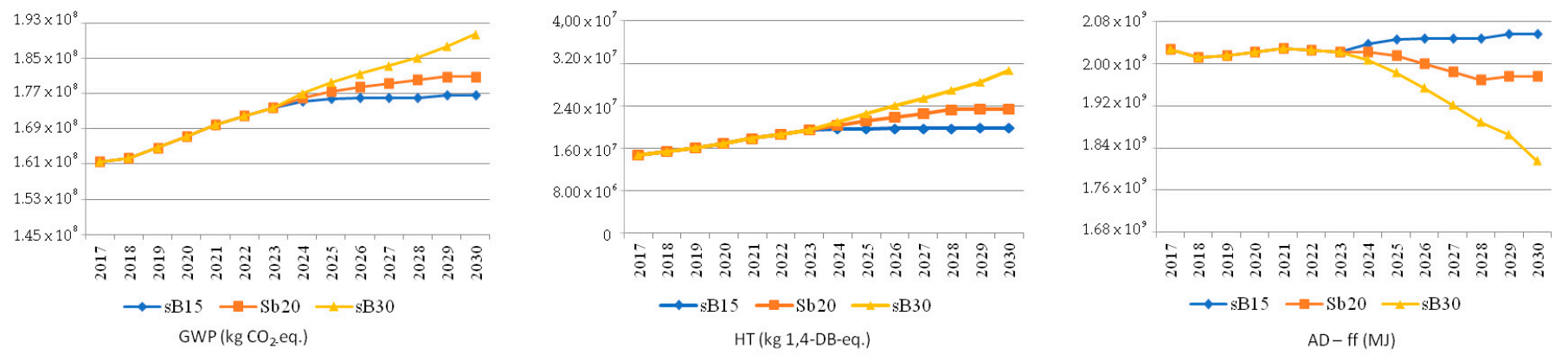

Figure 5. Impact projections of the Global Warming Potential (GWP) (in kg CO 2 eq.), Human Toxicity (Ht) (in kg 1,4-DBeq.), Abiotic Depletion fossil fuels (MJ) for the public transportation in the city of Porto Alegre per year from fleet replacements and fuel changes among scenarios 1,2 , and 3.

\section{Conclusions}

The study shows that fuel substitution in both GWP and HT generates an increase in emissions for the transportation system, where in $\mathrm{AD}$ a decrease is noticed. The research also indicates that a trend between fleet efficiency and travel scenarios is most noticeable in years that have a higher number of vehicle substitutions. The increase in impacts correlated to the increment of biodiesel to the mix, especially in HT, in which it is confirmed the magnitude of impacts generated by heightening the percentage of biodiesel. Additionally, according to the results of this research, the federal laws on biofuel production are those 
that have greater influence over the public bus transportation and its impacts, yet scrutiny of other particularities of the system is paramount to identify accurate and appropriate courses of action in the municipalities. Hence, several strategies to mitigate impacts on transport must be considered, allowing for a technological evolution that reduces negative impacts, whether through changes in fuel or fleet electrification.

More than the practical results of the case study, the study showed that when conducting a LCA to support decision-making in urban public services, a detailed approach is needed, considering that technological variables interact directly with the territorial context in a complex network in which changes in laws and changing user behaviors interact. Therefore, the essential aspects of the TLCA modeling for impact assessment were used to consider all the factors that can actually produce a shift in the current scenario and support policies geared toward the achievement of the goals for sustainable development.

Supplementary Materials: The following are available online at https:/ / www.mdpi.com/article/ 10.3390/infrastructures6120169/s1, Interview PTCC: Stakeholder Interview Report, Table S1: Fleet replacement changes (in vehicle units).

Author Contributions: The manuscript was written through the contributions of all authors, as follows: Conceptualization, M.L. and I.H.; methodology, M.L., I.H. and A.P.; software, M.L. and I.H.; validation, M.L. and A.P.; formal analysis, M.L. and I.H.; investigation, M.L. and I.H.; resources, M.L. and I.H.; data curation, M.L.; writing—original draft preparation, M.L. and I.H.; writing-review and editing, M.L. and A.P.; visualization, A.P.; supervision, A.P.; project administration, A.P.; funding acquisition, A.P. All authors have read and agreed to the published version of the manuscript.

Funding: The participation of A.P. is sponsored by the National Council for Scientific and Technological Development-Brazil (CNPq) through the research fellowships PQ 2018: Grant number 306045/2018-4 and Universal: grant number: 429264/2018-6. The participation of M.L. is sponsored by the Coordination for the Improvement of Higher Education Personnel (CAPES) through the research scholarship 2020: File number: 429264/2018-6.

Institutional Review Board Statement: Not applicable.

Informed Consent Statement: Not applicable.

Data Availability Statement: Not applicable.

Acknowledgments: The authors acknowledge the financial support from CAPES (Coordination for the Improvement of Higher Education Personnel) and CNPq (National Council for Scientific and Technological Development-Brazil). The participation of A.P is sponsored by CNPq through the research fellowships PQ 2018: Grant number 306045/2018-4 and Universal: grant number: 429264/2018-6. The participation of M.L is sponsored by Capes through the research scholarship 2020: File number: 429264/2018-6. Moreover, we would like to thank the Public Transport and Circulation Company (PTCC) — in Portuguese EPTC — for all the data provided to enable this research to be conducted.

Conflicts of Interest: The authors declare no conflict of interest.

\section{References}

1. AR5 Climate Change 2014: Mitigation of Climate Change. IPCC—Internacional Painel for Climate Change. 2014. Available online: https://www.ipcc.ch/report/ar5/wg3/ (accessed on 1 October 2021).

2. Markvica, K.; Hu, B.; Prandtstetter, M.; Ritzinger, U.; Zajicek, J.; Berkowitsch, C.; Hauger, G.; Pfoser, S.; Berger, T.; Eitler, S.; et al. On the Development of a Sustainable and Fit-for-the-Future Transportation Network. Infrastructures 2018, 3, 23. [CrossRef]

3. Institute of Energy and Environment-IEE (in portuguese IEMA). Brazilian Emissions of Greenhouse Gases in the Energy and Industrial Processes Sectors in 2019; Institute of Energy and Environment-IEE (in portuguese IEMA): São Paulo, Brazil, 2020.

4. Hackenhaar, I.C. Life Cycle Assessment to Support Public Policies for Sustainable Urban Development: A Case Study of the Collective Public Transport System in Porto Alegre. 2020. Available online: https:/ /www.lume.ufrgs.br/handle/10183/213543 (accessed on 22 August 2021).

5. Albertí, J.; Balaguera, A.; Brodhag, C.; Fullana-I-Palmer, P. Towards Life Cycle Sustainability Assessent of Cities. A Review of Background Knowledge. Sci. Total Environ. 2017, 609, 1049-1063. [CrossRef] [PubMed]

6. Petit-Boix, A.; Llorach-Massana, P.; Sanjuan-Delmás, D.; Sierra-Pérez, J.; Vinyes, E.; Gabarrell, X.; Rieradevall, J.; Sanyé-Mengual, E. Application of Life Cycle Thinking towards Sustainable Cities: A Review. J. Clean. Prod. 2017, 166, 939-951. [CrossRef] 
7. Loiseau, E.; Aissani, L.; Le Féon, S.; Laurent, F.; Cerceau, J.; Sala, S.; Roux, P. Territorial Life Cycle Assessment (LCA): What Exactly Is It about? A Proposal towards Using a Common Terminology and a Research Agenda. J. Clean. Prod. 2018, 176, 474-485. [CrossRef]

8. Ramaswami, A.; Weible, C.; Main, D.; Heikkila, T.; Siddiki, S.; Duvall, A.; Pattison, A.; Bernard, M. A Social-EcologicalInfrastructural Systems Framework for Interdisciplinary Study of Sustainable City Systems. J. Ind. Ecol. 2012, 16, 801-813. [CrossRef]

9. Loiseau, E.; Roux, P.; Junqua, G.; Maurel, P.; Bellon-Maurel, V. Implementation of an Adapted LCA Framework to Environmental Assessment of a Territory: Important Learning Points from a French Mediterranean Case Study. J. Clean. Prod. 2014, 80, 17-29. [CrossRef]

10. ISO. ISO 14040—Environmental Management_Life Cycle Assessment—Principles and Framework. 2006. Available online: https: / / www.iso.org/standard/37456.html (accessed on 2 October 2021).

11. Brustad, T.F.; Dalmo, R. Railway Transition Curves: A Review of the State-of-the-Art and Future Research. Infrastructures 2020, 5, 43. [CrossRef]

12. Chester, M.V.; Nahlik, M.J.; Fraser, A.M.; Kimball, M.A.; Garikapati, V.M. Integrating Life-Cycle Environmental and Economic Assessment with Transportation and Land Use Planning. Environ. Sci. Technol. 2013, 47, 12020-12028. [CrossRef]

13. François, C.; Gondran, N.; Nicolas, J.-P.; Parsons, D. Environmental Assessment of Urban Mobility: Combining Life Cycle Assessment with Land-Use and Transport Interaction Modelling-Application to Lyon (France). Ecol. Indic. 2017, 72, 597-604. [CrossRef]

14. Vedrenne, M.; Pérez, J.; Lumbreras, J.; Rodríguez, M.E. Life Cycle Assessment as a Policy-Support Tool: The Case of Taxis in the City of Madrid. Energy Policy 2014, 66, 185-197. [CrossRef]

15. Clark, S.S.; Chester, M.V. A Hybrid Approach for Assessing the Multi-Scale Impacts of Urban Resource Use: Transportation in Phoenix, Arizona. J. Ind. Ecol. 2017, 21, 136-150. [CrossRef]

16. Brazilian Institute of Geography and Statistics-BIGS (in portuguese IBGE). IBGE Cidades. 2018. Available online: https: / / cidades.ibge.gov.br/brasil/rs/porto-alegre/panorama (accessed on 1 August 2021).

17. Brazilian Government. Resolution No 10 257, de 10 July of 2001. In City Statute and Related Legislation. 2. ed. (p. 80). Federal Senate, Undersecretary of Technical Editions; 2002. Available online: http://www.planalto.gov.br/ccivil_03/leis/leis_2001/110257.htm (accessed on 12 August 2021).

18. Porto Alegre Municipal Secretariat for the Environment and Sustainability- PAMSES (in portuguese SMAMS). Presentation: Review of the UN Master Plan and Sustainable Development Goals (SDGs); 34 a Semana do Meio Ambiente. Available online: http://lproweb.procempa.com.br/pmpa/prefpoa/cs/usu_doc/semanaambiente34.pdf (accessed on 29 August 2021).

19. Porto Alegre City Hall—PACH (in portuguese PMPA). (2019a). Diagnosis of Mobility in the Municipality of Porto Alegre and its Metropolitan Interface. 2019. Available online: https://prefeitura.poa.br/sites/default/files/usu_doc/projetos/smim/Plano\% 20de\%20Mobilidade\%20Urbana/Relatorio_PMU_Diagnostico_da_Mobilidade_0.pdf (accessed on 29 August 2021).

20. Porto Alegre City Hall—PACH (in portuguese PMPA). Prognosis of Mobility in the Municipality of Porto Alegre: Vol. Primeira. 2019. Available online: https:/ / prefeitura.poa.br/sites/default/files/usu_doc/projetos/smim/Plano\%20de\%20Mobilidade\% 20Urbana/5_Prognostico_da_Mobilidade_versao\%20atualizada.pdf (accessed on 21 August 2021).

21. Leichter, M.; Hackenhaar, I.; Passuello, A. Assessment of Environmental Impacts Related to Urban Mobility: Case Study Considering Two Neighborhoods in the City of Porto Alegre. In Proceedings of the Blucher Engineering Proceedings; II National Symposium on Urban Management and Engineering: São Paulo, Brazil, 2019; Volume 6, pp. 810-817.

22. Promised for October, Renewal of Carris' Bus Fleet is Due Next Year. Zero Hora. Porto Alegre. 2019. Available online: https:/ / gauchazh.clicrbs.com.br/porto-alegre/noticia/2019/10/prometida-para-outubro-renovacao-da-frota-de-onibusda-carris-fica-para-o-ano-que-vem-ck2aywi5t01wj01n3veugd25r.html (accessed on 20 August 2021).

23. Silva, F.B.; Yoshida, O.S.; Diestelkamp, E.D.; De Oliveira, L.A. Relevance of including capital goods in the life cycle assessment of construction products. In LALCA: Revista Latino-Americana Em Avaliação Do Ciclo de Vida; 2(2 esp.); 2018; pp. 7-22. [CrossRef]

24. Brazilian Association of Technical Standards-BATS (in portuguese ABNT). NBR ISO 37120: Sustainable Community Development-Indicators for Urban Services and Quality of Life. 2017. Available online: https://www.abntcatalogo.com. br/norma.aspx?Q=YVRxRmZPakRQZWZrQzdTRk1PVzVzaXVVY3BQaHhrVHINYXR3WFNmU0FSQT0= (accessed on 18 August 2021).

25. Brasil. National Voluntary Report on Sustainable Development Goals. In Government Secretariat of the Presidency of the Republic, Ministry of Planning, Development and Management; 2017. Available online: https://exposicao.enap.gov.br/items/show/562 (accessed on 18 August 2021).

26. Nordelöf, A.; Romare, M.; Tivander, J. Life Cycle Assessment of City Buses Powered by Electricity, Hydrogenated Vegetable Oil or Diesel. Transp. Res. Part D Transp. Environ. 2019, 75, 211-222. [CrossRef]

27. Brazilian Government. Resolution No 13 263, de 23 March of 2016. In Secretaria-Geral Subchefia para Assuntos Jurídicos; 2016. Available online: http://www.planalto.gov.br/ccivil_03/_ato2015-2018/2016/lei/113263.htm (accessed on 18 August 2021).

28. National Petroleum Agency, Natural Gas and Biofuels-NPA (in portuguese ANP) Resolution ANP No 30, DE 23.6.2016. Official Diary of the Union. 2016. Available online: http:/ /legislacao.anp.gov.br/?path=legislacao-anp/resol-anp/2016/junho\&item= ranp-30-2016\&export=pdf (accessed on 18 August 2021). 
29. Public Transport and Circulation Company-PTCC (in portuguese EPTC). Consumption, Running and Number of Passengers Data Provided on Demand in the Month of November 2018-Values for the years 2017-2018. 2018. Available online: http: / /www2.portoalegre.rs.gov.br/eptc/ (accessed on 18 August 2021).

30. ECOINVENT. Ecoinvent Database-Version 3.6. 2020. Available online: https://ecoinvent.org/home.html (accessed on 10 August 2021).

31. National Energy Balance-NEB (in portuguese BEN). Base year 2019. 2020. Available online: https://ben.epe.gov.br/ (accessed on 15 August 2021).

32. Elkelawy, M.; Alm-Eldin Bastawissi, H.; Esmaeil, K.K.; Radwan, A.M.; Panchal, H.; Sadasivuni, K.K.; Ponnamma, D.; Walvekar, R. Experimental Studies on the Biodiesel Production Parameters Optimization of Sunflower and Soybean Oil Mixture and DI Engine Combustion, Performance, and Emission Analysis Fueled with Diesel/Biodiesel Blends. Fuel 2019, 255, 115791. [CrossRef]

33. Viana, M.M. Sunflower Oil Ethyl Biodiesel Life Cycle Inventory; Mestrado em Engenharia Química; Universidade de São Paulo: São Paulo, Brazil, 2008.

34. Teixeira, E.C.; Feltes, S.; de Santana, E.R.R. Study of emissions from mobile sources in the metropolitan region of Porto Alegre, Rio Grande do Sul. Quím. Nova 2008, 31, 244-248. [CrossRef]

35. Da Costa, R.S. Quantification of Greenhouse Gas Emissions for Household Waste Collection Vehicles Fueled with CNG and DieselB5 Using Life Cycle Assessment (LCA). 2016. Available online: http://tede2.pucrs.br/tede2/handle/tede/7859?mode=full (accessed on 12 August 2021).

36. UN-United Nations. Transforming our World: The 2030 Agenda for Sustainable Development. General Assembly, Seventieth Session; A/RES/70/1; Agenda items 15 and 116. 2015. Available online: https://www.un.org/ga/search/view_doc.asp? symbol=A/RES/70/1\&Lang=E (accessed on 13 August 2021).

37. Fazio, S.; Castellani, V.; Sala, S.; Schau, E.M.; Secchi, M.; Zampori, L.; Diaconu, E. Supporting Information to the Characterisation Factors of Recommended EF Life Cycle Impact Assessment Method. New Models and Differences with ILCD. EUR 28888 EN. Insititute of Environment and Sustainibility (p. 42). 2018. European Commission. Available online: http://www.jrc.ec.europa.eu/ (accessed on 23 November 2021).

38. Mendes, N.C.; Bueno, C.; Ometto, A.R. Life Cycle Impact Assessment: Review of main methods. Production 2015, 26, 160-175. [CrossRef]

39. Tabatabaei, M.; Aghbashlo, M.; Najafi, B.; Hosseinzadeh-Bandbafha, H.; Faizollahzadeh Ardabili, S.; Akbarian, E.; Khalife, E.; Mohammadi, P.; Rastegari, H.; Ghaziaskar, H.S. Environmental Impact Assessment of the Mechanical Shaft Work Produced in a Diesel Engine Running on Diesel/Biodiesel Blends Containing Glycerol-Derived Triacetin. J. Clean. Prod. 2019, 223, 466-486. [CrossRef]

40. Nanaki, E.A.; Koroneos, C.J. Comparative LCA of the Use of Biodiesel, Diesel and Gasoline for Transportation. J. Clean. Prod. 2012, 20, 14-19. [CrossRef]

41. Nocker, L.; Spirinckx, C.; Torfs, R. Comparison of LCA and external-cost analysis for biodiesel and diesel. In Proceedings of the 2nd International Conference LCA in Agriculture, Agro-Industry and Forestry, Brussels, Belgium, 3-4 December 1998; pp. 1-10.

42. Viornery-Portillo, E.A.; Bravo-Díaz, B.; Mena-Cervantes, V.Y. Life Cycle Assessment and Emission Analysis of Waste Cooking Oil Biodiesel Blend and Fossil Diesel Used in a Power Generator. Fuel 2020, 281, 118739. [CrossRef]

43. IBGE-Instituto Brasileiro de Geografia e Estatística. Indicators for Sustainable Development Goals. 2018. Available online: https: / / www.ibge.gov.br/geociencias/informacoes-ambientais/estudos-ambientais/15838-indicadores-de-desenvolvimentosustentavel.html (accessed on 1 August 2021).

44. Cano, A.; Chester, M. Time-Based Life-Cycle Assessment for Environmental Policymaking: Greenhouse Gas Reduction Goals and Public Transit. Transp. Res. Part D Transp. Environ. 2015, 43, 49-58.

45. Garcia, R.; Gregory, J.; Freire, F. Dynamic fleet-based life-cycle greenhouse gas assessment of the introduction of electric vehicles in the Portuguese light-duty fleet. Int. J. Life Cycle Assess. 2015, 20, 1287-1299. [CrossRef]

46. Albertí, J.; Brodhag, C.; Fullana-i-Palmer, P. First Steps in Life Cycle Assessments of Cities with a Sustainability Perspective: A Proposal for Goal, Function, Functional Unit, and Reference Flow. Sci. Total Environ. 2019, 646, 1516-1527. [CrossRef] [PubMed]

47. Maricato, E.; To Understand the Urban Crisis. Expressão Popular. 2016. Available online: https://periodicos.furg.br/cnau/ article/view/5518 (accessed on 2 August 2021).

48. Weidema, B.P.; Ekvall, T.; Pesonen, H.-L.; Rebitzer, G.; Sonnemann, G.; Spielmann, M. Scenarios in Life-Cycle Assessment (p. 88). Society of Environmental Toxicology and Chemistry (SETaC). 2004. Available online: https://lca-net.com/publications/show / scenarios-life-cycle-assessment/ (accessed on 20 August 2021).

49. Scholz, R.W.; Tietje, O. Embedded Case Study Methods: Integrating Quantitative and Qualitative Knowledge; Sage Publications: Thousand Oaks, CA, USA, 2002; ISBN 978-0-7619-1945-2. 